\title{
A FORMAÇÃO DO PROFESSOR EM FACE DAS VIOLÊNCIAS DAS/NAS ESCOLAS
}

\section{CANDIDO ALBERTO GOMES}

Titular da Cátedra sobre Juventude, Educação e Sociedade

da Universidade Católica de Brasília

clgomes@terra.com.br

\section{MARLENE MONTEIRO PEREIRA}

Professora da Universidade Católica de Brasília e Secretária Executiva da Cátedra sobre Juventude, Educação e Sociedade da Universidade Católica de Brasília e do Observatório de Violências nas Escolas

marlene.m.pereira@gmail.com

\section{RESUMO}

O desvelamento das violências das/nas escolas levou ao desenvolvimento de numerosas pesquisas sobre a formação inicial e continuada de professores. Parte destas analisa a socialização profissional do magistério e encontra questões como as novas faces do "choque de realidade" dos docentes. Assim, efetuou-se uma investigação sobre as percepções dos licenciandos a respeito das violências e de seu próprio preparo. Os resultados, obtidos por meio de grupos focais realizados com licenciandos, confirmam a sensação de despreparo para a imersão, ainda que gradual, na prática. Entre as propostas dos participantes, destacam-se a construção de um gradiente teoria-prática mais adequado, o caráter mais aplicado das disciplinas e o desenvolvimento da capacidade de encontrar soluções, sem receituários.

FORMAÇÃO DE PROFESSORES - VIOLÊNCIA - ESCOLAS - SOCIOLOGIA DA EDUCAÇÃO

\section{ABSTRACT}

TEACHER EDUCATION IN FACE OF VIOLENCE FROM/AT SCHOOLS. The unveiling of violence from/at schools has led to the development of research on initial and continued teacher education. Some analyze the professional socialization of teachers and find issues such as the new faces of

Pesquisa realizada pelo Observatório de Violências nas Escolas - Brasil (Unesco/Universidade Católica de Brasilia) e pela Cátedra sobre Juventude, Educação e Sociedade da mesma Universidade. Agradecemos a imprescindível colaboração do professor Marcos Grams e a participação dos mestrandos em educação Christina Pereira da Silva, Eliana Maria Sarreta Alves, Eliana Pessoa, Eny da Luz Lacerda Oliveira, Ive Carina R. L. Brasil, Fernanda M.C. Fernandes, Hudson Eloy Braga, Luciana Mendonça Gottschall, Maria Orlene Alves, Natsuko Sato, Paula Fernanda de Melo Rocha e Walderlene Silva Gomes. 
the "reality shock" by teachers. Thus, an investigation on the perceptions of teachers on types of violence and on their own preparedness for teaching has been conducted. The results, obtained by means of focus groups carried out with teachers, confirm the perception that they are not prepared to experience the practice of teaching, even if gradually. Among the proposals presented by participants, we should point out the construction of a more adequate gradient between theory and practice, the more practical nature of courses and the development of the capacity to find solutions without ready recipes.

TEACHER EDUCATION - VIOLENCE - SCHOOL - SOCIOLOGY OF EDUCATION

O desenvolvimento das ciências da educação e as transformações da sociedade e dos sistemas escolares levaram a uma preocupação marcante com as violências. Não que elas não existissem antes, mas porque, em parte, se encontravam veladas. Hoje, sua face mais visível é a das graves agressões físicas, incluindo múltiplos homicídios, praticadas por alunos contra colegas e professores. Entretanto, são menos notadas as violências praticadas pela escola e pelos professores contra os alunos e, em certos casos, contra os pais e as comunidades. Elas incluem desde chicotes sobre as mesas de numerosos professores em países da África Subsaariana - não para usá-los, mas para "dissuadir" comportamentos dos alunos, dizem eles (Chupin, 2006) - até os intrincados processos de violência simbólica que conduzem ao fracasso escolar (Dubet, Martuccelli, 1996). Na via de mão dupla, também os alunos praticam entre si e contra o pessoal escolar violências físicas, simbólicas e incivilidades (Debarbieux, Blaya, 2002).

Um dos pontos-chave para compreender esses fatos e criar uma cultura de paz nas escolas é a preparação do professor, inicial e continuada. Será que o professor tem condições, no pensamento e na ação, na compreensão teórica e nas estratégias, de fazer face às violências, inclusive tomando consciência daquelas que a própria escola prática, entre elas as de ordem simbólica? E quanto aos futuros professores, nos cursos de licenciatura, quais suas opiniões e expectativas sobre os cursos que os formam?

Sendo o docente uma liderança estratégica da escola, o decisor na sala de aula, é importante que esteja capacitado a agir perante violências, não com receituários e recursos aprendidos por ensaio e erro, mas com a compreensão científica dos fatos, de modo a poder intervir e efetivamente liderar o processo educativo. Em contraste, a literatura brasileira (Pereira, 1963), assim como a internacional, revela o choque transicional do professor que sai da instituição 
A formação do professor..

formadora para a prática da sala de aula. É possível que esse choque se tenha agravado com as novas condições de trabalho dos docentes e o desgaste físico e psicológico da ocupação. No entanto, não se sabe se e em que medida os currículos e programas de preparação atendem às necessidades do pessoal, nem se a educação continuada preenche as lacunas. Assim, é relevante investigar a instituição formadora do magistério, o que se tem feito, que lições se tem a aprender e que necessidades precisam ser contempladas.

\section{OBJETIVO DA PESQUISA}

Esta pesquisa visou identificar as necessidades manifestas por licenciandos da Universidade Católica de Brasília sobre sua formação inicial, em face das violências nas escolas e da construção de uma cultura de paz. Assim, o trabalho se propôs a ouvir e fomentar o debate sobre a formação inicial enquanto os participantes faziam estágio, tendo ou não experiência de magistério. Além de falar de suas necessidades, os sujeitos da pesquisa foram convidados a apresentar e discutir, a partir das suas experiências, propostas sobre como deveria ser a formação inicial adequada às circunstâncias. Com isso, a Universidade também se autoavalia. Os resultados devem obedecer à "generalização naturalística"' . Eles têm uma parte imanente à realidade da instituição, por suas peculiaridades e as de seu contexto social imediato. Outra parte transcende à sua realidade, na medida em que a Universidade segue uma legislação e políticas comuns a todas as instituições de educação superior para formar educadores.

\section{OS PROFESSORES E AS VIOLÊNCIAS}

A literatura dedica importantes reflexões e pesquisas ao papel do professor em face das violências escolares, tanto no Brasil como em outros países. Além das mudanças da sociedade inclusiva, a escola se transformou em instituição de massa e compulsória, pelo menos até certo nível. Matricular-se

I. A generalização naturalística é semelhante a um espelho: na medida em que o meu caso se reflete e se identifica no caso apresentado no relatório de pesquisa, posso, com prudência, aplicar e adaptar as suas conclusões ao meu caso, nunca esquecendo que a imagem refletida pode sofrer distorções. 
nela antes era uma esperança concreta de futuro melhor e, ao mesmo tempo, privilégio quase exclusivo das elites. Hoje ser aluno é simultaneamente um direito e um dever constitucionais e legais. Não importa se o discente ou a família deseja a matrícula, pois ela é obrigatória, não só por lei, mas também pela necessidade social de se escolarizar para não ser excluído ou agravar a exclusão social: quanto mais educação se tem, mais educação é necessária e mais tempo é preciso permanecer na escola, num processo crescente. Assim, esses fenômenos resultaram da perturbação dos acordos entre os diferentes níveis do sistema educacional e os públicos que lhes eram socialmente destinados (Barrère, Sembel, 2002). Por isso, não é de surpreender que as violências se tornem uma problemática nova em suas dimensões e manifestações (Chrispino, Chrispino, 2002).

Uma pesquisa seminal, já na década de 1960, abordou as mudanças da indisciplina nas escolas secundárias da França, que se democratizaram aceleradamente. Testanière (1967) distinguiu a indisciplina tradicional da indisciplina anômica. A primeira ocorria em escolas burguesas, onde os alunos aderiam à ordem pedagógica. A função da indisciplina era expressar e reforçar a integração dos alunos aos grupos de colegas. Era uma espécie de transgressão regulamentada, necessária ao bom funcionamento do sistema pedagógico tradicional, visto que aliviava as tensões. A indisciplina anômica ocorria em escolas cujo alunado era de baixo status socioeconômico e tinha como principal objetivo não o aproveitamento, mas o diploma, encarado como meio de ascensão social. Tal tipo de indisciplina surgia quando mais de um terço dos alunos matriculados na escola provinham da classe trabalhadora. A indisciplina não tinha plano prévio, líderes ou respeito a regras, mas apenas alunos "populares".

Uma das grandes questões é que não se consegue realizar o processo educativo e a aprendizagem sem um mínimo de ordem na sala de aula e no estabelecimento educacional. Tal ordem, imposta pela escola tradicional, relativamente homogênea, não funciona mais. É preciso, então, que toda a comunidade educativa compartilhe definições comuns das situações conflituosas e pactue um sistema mínimo de normas de convivência social, o que é uma missão difícil (Gomes, 2005).

Os tipos tradicional e anômico de indisciplina correspondem às variações do processo de subjetivação dos alunos de diferentes classes sociais, conforme as pesquisas de Dubet $(2002,2003)$ e Dubet, Martuccelli (1996). De modo 
A formação do professor..

geral, independentemente do status socioeconômico, o protagonismo dos jovens cresceu, sobretudo a partir do pós-guerra, contribuindo para culturas adolescentes e juvenis que se fortalecem em oposição à cultura escolar e aos variados tipos de arranjos familiares.

Nessas novas circunstâncias, a socialização deixou de ser vista como um processo em que uma geração transmite à outra a herança sociocultural, como o atleta que passa a tocha olímpica adiante. A socialização se tornou a construção da experiência individual (subjetivação) dos alunos, interagindo tanto com a cultura escolar quanto com as culturas adolescentes/jovens. Os alunos socialmente aquinhoados, menos distantes da cultura da escola, são capazes de se integrar às culturas juvenis com limitados desafios à ordem escolar. Em contraste, os alunos menos privilegiados e mais afastados da cultura escolar enfrentam problemas de fracasso e de falta de sentido dos currículos, que os levam ao conflito aberto com a ordem da escola.

Assim, não é de estranhar que numerosos professores detestem seus alunos, que sofram de burnout ${ }^{2}$ e que alunos rejeitem colegas que os agridem e perturbam o clima escolar, prejudicando a aprendizagem (Abramovay, Rua, 2002). A escola não raro se torna um grupo estilhaçado, em que uns não suportam os outros e em que currículos e regulamentos não fazem muito sentido, renunciando-se, assim, às oportunidades educativas de "aprender a conviver". Tais condições constituintes da vida escolar, se traduzem em grande parte no desinteresse dos alunos; na sistemática falta de respeito dos discentes para com os professores e funcionários, que perderam grande parte da sua autoridade, esta frequentemente talhada à moda antiga; na indiferença dos estudantes pela presença do professor em sala de aula, como se este fosse uma coisa inanimada, e na sala de aula como cenário de agressão contra o professor, conforme constataram Abramovay et al. (2006).

É interessante enfatizar nessa pesquisa que as principais causas de ameaças aos professores por parte dos alunos foram a reprovação e as notas baixas, o que se relaciona não só ao arriscado declínio do conceito de mérito, como também ao papel da escola como matriz reprodutora da exclusão social, manifestando as violências simbólica e institucional, mais veladas que as físicas.

2. A síndrome de burnout, identificada na década de 1970, caracteriza-se por exaustão emocional, despersonalização e redução da realidade pessoal. 
Em tais contextos sociais, o professor e demais educadores tendem a ser algozes e vítimas. Como lembra Soeiro (2003), existe não somente a violência na escola, mas também a violência pela escola e a violência para com a escola, o que torna esta última também simultaneamente vítima e produtora de violência. Barroso (2003) destaca que a relação entre disciplina e aprendizagem tem a sua gênese na organização pedagógica escolar pública. Sendo disciplina e indisciplina igualmente violentas, a violência está, pois, na raiz da organização escolar. Entretanto, pelo menos uma pesquisa empírica evidencia que o conceito de violência do professor enfatiza mais a de tipo físico que a de tipo simbólico, além de ter um viés em favor do próprio grupo docente quanto à legitimidade de praticar certos atos (Oliveira, Gomes, 2004).

Em suma, o mundo e a sociedade mudaram em torno da escola. Os alunos participam de vários círculos sociais, com culturas não raro conflitantes que se enfrentam dentro e fora da instituição escolar, reforçando seu caráter de arena, ou de arenas superpostas. A participação do discente depende de negociação, enquanto a autoridade de que o professor estava investido tradicionalmente já não é respeitada. Em outras palavras, novas sociedades requerem novas escolas e novos professores.

\section{O PROFESSOR E O CHOQUE DE REALIDADE}

Clássicos como Lortie (2002) apontam especificidades do magistério e da socialização do professor na formação inicial e no trabalho. As ocupações modelam de certo modo as pessoas e desenvolvem uma cultura própria, como a de médico, advogado, engenheiro etc. Entretanto, a preparação do magistério, como se conhece, é recente e tem conexões débeis com as correntes do desenvolvimento intelectual nas sociedades modernas. $O$ que os estudantes aprendem é em grande parte intuitivo e imitativo, em vez de explícito e analítico. Como uma arte, tendem a aprendê-la na prática, isoladamente, confinados às salas de aula, cujas portas, uma vez fechadas, reduzem a visibilidade do professor e a comunicação com os colegas.

Ao contrário dos cirurgiões, os professores, uma vez formados, passam abruptamente à plena responsabilidade da sala de aula: ou nadam ou afundam. Além disso, o início da carreira se caracteriza pelo "choque de realidade", velho conhecido da literatura, e pela provação vivida em relativo isolamento, que 
A formação do professor..

contribui para o conservantismo. Não é surpreendente que os formados considerem as licenciaturas como muito teóricas, compostas de cursos repetitivos e maçantes, tendo conteúdo intelectual ralo. Declaram que elas apresentam expectativas transcendentais nos estudantes sem prover-lhes os meios para alcançá-las. Falta, portanto, uma base teórico-prática adequada, ao contrário de várias profissões (Lortie, 2002).

Como Foracchi (1960) abordou há décadas, esse é o difícil processo de socialização vivido desde a formação inicial até a inserção plena no grupo docente. Vale lembrar que os professores são alvo não só da violência dos alunos, mas também dos colegas. Por trás do pacto de silêncio, há evidências de que grupos docentes passam o rolo compressor sobre aqueles que se afastam da conduta prescrita, entre eles os inovadores e os "novatos", recorrendo a diversos tipos de violência, entre eles o assédio moral e perseguições (Blaya, 2006).

No Brasil, como em outros países, esse choque é agravado pela destinação das turmas mais "difíceis" aos professores iniciantes (Freitas, 2002). A concorrência entre os docentes, regulamentada por planos de carreira e outros documentos, leva aqueles com maior experiência a ensinar aos alunos mais privilegiados. Quanto aos alunos que "não conseguem aprender", cujo fracasso é atribuído às origens sociais e familiares, são atribuídos professores iniciantes confirmando o ditado: a corda arrebenta do lado mais fraco.

$\bigcirc$ hiato entre a profissão como se imagina e o que ela realmente é conduziu a mudanças na formação inicial do magistério. Dentre as diversas experiências, uma pesquisa comparativa assinalou que, na Inglaterra, os alunosmestres se formam numa espécie de curso sanduíche, utilizando $80 \%$ do tempo em escolas, em experiências variadas, com o apoio dos melhores professores, e o restante na universidade. É bem verdade que Young (1999) assinalou, entre outras limitações, a falta de visão ampla do currículo e da sua integração, bem como a perspectiva de aprendizagem decomposta no desenvolvimento de habilidades específicas.

Em contraste, a França tem uma formação centrada nas instituições de educação superior, que, apesar dos obstáculos, introduziu oficinas e dramatizações, inclusive sobre as violências nas escolas. Na Inglaterra, as escolas tendem a constituir equipes mais estáveis de educadores, com apoio dos colegas e supervisores aos iniciantes. Já na França o isolamento da sala de aula e a solidão dos novos docentes são significativamente maiores (Blaya, 2003), o 
que leva a uma intensa auto-socialização no primeiro ano de trabalho (DuruBellat; Van Zanten, 2006).

$\mathrm{Na}$ Holanda, foi avaliado um programa para formação de professores, com acompanhamento dos alunos desde a matrícula inicial até o terceiro ano de profissão. Tal programa consta de estágios cada vez mais longos, enlaçando teorias e práticas. As experiências são discutidas em pequenos grupos e sessões plenárias. Cada supervisor da universidade acompanha entre três e cinco tríades de alunos, que são visitadas no mínimo duas vezes por semana, frequentemente mais. $O$ processo culmina com um estágio de 13 horas por semana, durante seis meses, supervisionado por um professor mentor da escola, que se mantém ausente da sala de aula.

Supervisores e mentores trabalham para que a introdução à profissão se faça passo a passo. Os resultados mostram que, apesar disso, os egressos ainda sentem certa descontinuidade entre a instituição formadora e a realidade escolar. Ainda assim, as conclusões reforçam pesquisas anteriores sobre a importância das abordagens integradoras na formação docente, que fortalecem, inclusive, a capacidade de inovação dos novos mestres. $\bigcirc$ trabalho assinala que a formação efetivamente pode fazer diferença em relação ao tipo de capacidades desenvolvidas no curso universitário.

Essa diferença é alcançada por meio de: I . aumento gradual da complexidade das atividades; 2 . cooperação entre tríades, mentores e supervisores; 3. períodos alternados no estágio e na universidade, num todo coerente; 4. relacionamento não mecânicos entre teorias e práticas, mas por meio de complexa integração entre elas; e 5. construção de uma rampa suave para o início do exercício profissional.

Seja como for, a socialização do professor na sua ocupação continua a ter grande importância, a ponto de os que trabalham em áreas socialmente desfavorecidas não conseguirem se ressocializar para o trabalho em outras áreas, em vista de suas expectativas, metodologia e modos de manter a ordem na sala de aula (Duru-Bellat, Van Zanten, 2006). O processo socializador, a partir de incidentes críticos, conduz o docente a construir sua personalização do papel profissional, de maneira subjetiva. É daí que surgem tipos diferenciados de mestres que podem ser mais ou menos eficazes, sendo a liderança e o carisma de alta relevância (Felouzis, 2000).

No que se refere em particular às violências nas escolas, o professor se sente despreparado, o que agrava suas tensões e arruína sua saúde. Quer 
A formação do professor..

pelo tempo de carreira, quer pelas lacunas de sua formação inicial, quando se trata de programas para superar as violências nas escolas, o grupo docente torna-se alvo preferencial de ações de formação continuada. Isso é relatado em experiências da Espanha (Ortega, Rey, 2002; Ortega, 2002), da Bélgica (Blomart, 2002), da Grécia (Artinopolou, 2002) e de outros países, inclusive da América Latina (Filmus et al., 2003). Tendo como foco cada estabelecimento ou vários, esses programas procuram formar equipes escolares integradas, cujos membros não ajam isoladamente.

Com frequência tais programas, entre outros objetivos, buscam melhorar o relacionamento professor-aluno, estabelecer uma disciplina justa e coerente, auxiliar a administrar conflitos e criar um clima favorável ao processo educativo, à aprendizagem e, portanto, ao sucesso escolar, com a minimização dos desgastes de todos os grupos integrantes do que precisa constituir-se numa comunidade educativa.

Entretanto, existe um abismo entre o que oferece a pesquisa sobre violências nas escolas e sobre comportamentos agressivos e o que chega aos professores por meio da formação inicial e continuada. Royer (2003a), investigador da formação de docentes, confessa sua perplexidade ante o distanciamento pesquisa-prática, como se ainda estivéssemos no tempo da condenação de Galileu. Em contraste com a reatividade em face das violências, as medidas punitivas e o arsenal tecnológico para vigiar e punir, a literatura indica que os métodos exemplares para prevenir violências baseiam-se em um conjunto de valores compartilhados pelos educadores e os pais.

Por isso, as intervenções precisam de um modelo de referência capaz de explicar, predizer e compreender as violências, modelo que se estende além da escola, envolvendo a comunidade e serviços para a juventude. As regras precisam ser claras e definidas e, associadas a expectativas positivas e ao foco no reforço do desempenho escolar de cada aluno, tornam-se os elementoschave quando se ensina a discentes com problemas de comportamento. A abordagem punitiva, a aplicação improvisada de sanções no fogo dos acontecimentos, com base no senso comum, tende a aumentar as violências, não raro derrapando para o autoritarismo. Igualmente, não tem sentido culpar as famílias e as sociedades.

Royer (2002, 2003) advoga a formação docente com as mãos na massa, de modo a instruir a prática pela pesquisa e substituir a reatividade pela proati- 
vidade. Assim, distingue um conjunto de elementos essenciais que precisam ser integrados a qualquer estratégia para o desenvolvimento de conhecimentos e capacidades nos professores, visando evitar e lidar com a violência nas escolas. Em síntese, nove pontos são recomendados:

I. capacitar os professores a lidar com a violência escolar, incluindo medidas que assegurem que eles tenham conhecimento de como a violência se desenvolve nos jovens;

2. assegurar-se de que a escola é capaz de contribuir para a prevenção do desenvolvimento dos comportamentos agressivos;

3. defender uma abordagem ativa - e não reativa - no trato das violências, isto é, antecipar-se a elas, em vez de tomar providências depois que acontecem, e utilizar uma abordagem educativa, em vez de punitiva;

4. promover o desenvolvimento da capacidade de formular intervenções sob medida, sempre que necessário;

5. incentivar a formação continuada, sabendo que a experiência por si só não basta para evitar ou lidar com a violência;

6. assegurar-se de que os conhecimentos embasados nas conclusões das pesquisas recentes sejam transmitidos aos professores e integrados em suas atividades, juntamente com as práticas exemplares corroboradas por esses estudos;

7. dar prioridade ao desenvolvimento de uma abordagem construtiva na formação de parcerias com os pais;

8. reconhecer que a prevenção e o trato da violência são uma missão de toda a equipe escolar, na perspectiva de colaborar com os serviços oferecidos pela comunidade;

9. criar um mecanismo de avaliação que permita tratar dos novos problemas com os quais talvez os educadores venham a se confrontar e que, em graus variados, se relacionam à violência.

A distância entre esses nove pontos e os programas destinados à formação docente permite compreender porque professores consideram que sua preparação é divorciada da prática e que os cursos são excessivamente teóricos. Várias pesquisas, segundo Royer (2003), revelaram o interesse dos professo- 
A formação do professor..

res pela formação continuada que ofereça atividades formativas centradas em suas necessidades, que partam da vida escolar real e que desenvolvam neles capacidades aplicáveis à sua prática profissional. Nesse sentido, investigações apontaram o êxito de programas de formação de professores implantados diretamente no ambiente escolar, dotados do correspondente acompanhamento. Igualmente, constatou-se o sucesso de um modelo de auxílio mútuo entre professores de alunos adolescentes com problemas de adaptação. Um encontro semanal de 75 minutos permitia que pedissem conselhos aos colegas e formulassem uma intervenção a ser aplicada. No encontro seguinte, a experiência era relatada e avaliada.

Castro Santander (2005) ressaltou a necessidade de a formação inicial e continuada possibilitar ao docente o desempenho de suas distintas atividades, entre elas a criação de um clima escolar positivo e de novas estratégias de aproximação curricular que envolvam a educação em valores e atitudes prósociais, o desenvolvimento de estratégias de autocontrole e de resolução de conflitos. Em outros termos, a educação não pode deixar de lado dois dos quatro conhecidos pilares: aprender a conviver e aprender a ser (Delors et al., 2000), reduzindo-se a processos cognitivos, baseados na transmissão de conteúdos.

Portanto, a literatura focaliza a importância dos professores, enfatizando sua preparação para uma sociedade e uma escola que mudam continuamente. Urge, assim, inserir na formação inicial dos novos mestres os elementos necessários (embora não suficientes para superar as violências), a fim de que a formação continuada não seja um remendo na formação inicial. Tal preparação, conforme o primeiro princípio legal da formação de educadores na legislação brasileira, deve ser feita sob a égide do entrelaçamento de teorias e práticas.

Em suma, a literatura indica que, por um lado, a sociedade e os alunos estão mudando. Todo o trabalho da escola, a autoridade dos educadores e o relacionamento social precisam ser redefinidos. Não há como continuar com os velhos moldes. Por outro lado, a organização da escola e a formação de professores se mantêm, bem como as angústias inerentes, sobretudo, ao choque da realidade. Se hoje a pesquisa educacional está muito mais desenvolvida, sua presença nos currículos esmaece ou é em parte omitida, deixando de se associar às práticas. Continua-se a praticar a arte do magistério isoladamente nas salas de aula, buscando maior prática anterior. $\bigcirc$ descompasso entre so- 
ciedade e escola não é linear, como um corredor buscando reduzir a distância em relação ao colega à frente. $O$ hiato não se afigura simples, mas envolve diversas relações e faces complexas.

\section{METODOLOGIA}

Nesta primeira etapa da pesquisa, a coleta de dados foi feita por meio de seis grupos focais formados por licenciandos dos dois últimos períodos letivos da Universidade Católica de Brasília, compostos de dez a doze participantes, a maioria com experiência docente, conforme um roteiro prévio de discussão. Foram representados todos os cursos, exceto um. As falas foram gravadas, decodificadas e categorizadas. O trabalho, acompanhado sistematicamente pelos pesquisadores, foi em grande parte realizado por mestrandos em educação da própria universidade, como treinamento, depois de se fundamentarem na literatura e participarem ativamente da construção do projeto e do instrumento utilizado.

\section{RESULTADOS}

\section{Os primeiros contatos com as violências}

Quase todos os sujeitos tiveram contato com as violências. Vários deles escolheram propositalmente escolas de periferia, e não "escolas-modelo", para conhecer a realidade. Alguns casos logo afloraram, como o de um aluno que tinha tentado jogar uma pedra na cabeça da professora e que foi abordado também com violência por um segurança, no calor dos acontecimentos. Em outra escola o futebol entre os alunos mais parecia boxe, pois eles "acertavam tudo e todos, menos a bola". Emergiu das falas também a associação entre escolas de ambientes socialmente desprivilegiados e violências. De outro lado, as escolas particulares, quando bem ordenadas e dispondo de atenção e rigor com os alunos, foram consideradas relativamente pacíficas, embora se tenham registros de que lá também ocorriam violências, porque "o aluno paga a escola", isto é, comporta-se supostamente como consumidor.

Entre as duas pontas desse arco, situavam-se escolas públicas, mesmo em áreas de baixa renda, onde não havia "problemas", o que foi associado a estabelecimentos "bem estruturados", inclusive no que tange aos recursos 
A formação do professor..

disponíveis. Quanto ao turno, foram feitas menções divergentes, ora considerando os alunos do diurno mais interessados, ora, ao contrário, desinteressados e inquietos. No noturno, duas realidades foram diferenciadas: de um lado, os adultos com necessidade de escolarização, compenetrados do seu papel, e, de outro lado, os jovens envolvidos com o crime e o tráfico em áreas de gangues. Segundo a idade, os juízos divergiram muitas vezes, predominando a opinião de que os anos finais do ensino fundamental têm maior frequência de fatos violentos, o que corrobora outras pesquisas (Abramovay, Rua, 2002).

No que se refere aos tipos de violência, os participantes distinguiram a física e a simbólica, bem como as violências da escola e na escola, as últimas mais vivamente que as primeiras. Não se delineou a categoria de incivilidades (Debarbieux, 2007). $\bigcirc$ assédio ou bullying foi constatado por meio de "xingamentos" e de apelidos, muitas vezes sob a capa de "brincadeira". Igualmente, a hierarquia escolar, o poder do professor, o distanciamento de diretores em relação à escola, a utilização de ameaças ou a ridicularização de alunos diante das turmas foram não só detectados, como considerados mais abjetos que as violências dos alunos.

Vários licenciandos com maior concentração na formação pedagógica, como os de Pedagogia, chocaram-se com os fatos e tomaram atitudes positivas, procurando colocar-se no lugar dos alunos, que não raro tinham os pais atuando na criminalidade ou presos. Como resultado, verificaram-se ações como comunicação das regras do futebol, leitura participativa de livros de história e até um banho coletivo de mangueira, em que todos descobriram que podiam se divertir sem agressões. No dia seguinte, um menino desenhou as cenas e escreveu: "Estávamos todos brincando guntos [sic]".

As violências simbólicas e, em particular, as violências da escola foram menos evidentes. Os sujeitos da pesquisa não chegaram às filigranas do capital cultural, mas observaram não só as violências acima, como a omissão dos professores. Uma das observações mais contundentes foi a de uma escola pública onde o recreio era terra de ninguém: "A hora de recreio era hora de roubo, de pancadaria [...], era uma coisa horrível... Eu não via nenhum professor... Quando acontecia alguma coisa, o aluno ia até a sala dos professores e o professor dizia: 'Agora é minha hora, eu não sou professor agora'" (licencianda de Biologia).

Os motivos das violências, pontos estratégicos para atuarem como docentes (Royer, 2002), foram amplamente discutidos. Corroborando juízos 
acima sobre a localização das escolas mais e menos pacíficas, as violências foram vistas como reflexos das famílias e dos bairros em que vivem. Se as crianças, em seu processo de socialização, assistem ou participam de atos violentos na família e na vizinhança, aprendem que os valores subjacentes são "normais" e legítimos. Percebem que necessitam se defender a qualquer custo e, assim, formam grupos variados, entre eles as gangues.

Carência, pobreza, exclusão social e violências, portanto, estavam intimamente associadas, assim como as áreas que as concentram. Outro motivo destacado foi o dos grupos de colegas, que, de alguma forma, teriam relação com a autodefesa em ambientes hostis (o indivíduo não sobrevive só em ambientes competitivos-conflitivos entre grupos de iguais). Com frequência, apesar de valores contrários da família, adolescentes e jovens se reuniam em grupos e construíam padrões de conduta anti-social, envolvendo-se com a criminalidade, inclusive o uso e o tráfico de drogas, e praticando-a nos arredores ou no interior da escola. Quem não aceita os códigos está fora e sozinho, vulnerável aos ataques. Nesse sentido, vários sujeitos destacaram que a influência dos colegas leva a outros rumos, diferentes da educação da escola e da família, o que exige conhecer a dinâmica dos grupos de iguais (Gomes, 2005). De qualquer modo, isso se aplicaria, sobretudo, às áreas menos privilegiadas, com sua falta de oportunidades de emprego e trabalho.

O terceiro motivo citado foi a própria violência da escola, com professores desinteressados, insultuosos, arrogantes, que causam revolta em qualquer ambiente social, mas principalmente onde não se tem o que comer e grassam as violências. A escola seria reflexo de uma sociedade violenta, capitalista, logo, um objeto passivo. Nota-se que os fatores extra-escolares ocuparam uma posição notável na descrição, em detrimento dos fatores intra-escolares, secundarizados pelos participantes. Parece que já se formava a tendência de culpar o aluno, por suas origens sociais e outros motivos, e de absolver a escola (Mello, 1982) e a si mesmo, como professor, pelo fracasso. Despontariam, desse modo, os primeiros resultados da socialização profissional?

\section{O choque de realidade}

O choque de realidade começou no estágio, apesar de haver visitas e trabalhos em escolas já na primeira metade da licenciatura. Falou-se de "sus- 
A formação do professor..

to", de "tremer", de "frio na barriga", de "meu Deus, o que estou fazendo aqui?", de não saber como se portariam diante de uma turma, em especial nas escolas de áreas menos favorecidas. Confirma-se a persistência do hiato, entre a preparação do professor e a sua prática. Embora a literatura registre o fato há várias décadas, em particular quanto ao ensino normal, em linhas gerais ele permanece nas licenciaturas. Ou seja, elevou-se o nível da formação dos professores, mas o problema se manteve. Tal como em outros tempos, atribuiu-se a falta de preparo à formação inicial. Mesmo um licenciando com experiências docentes anteriores sentiu-se surpreendido e despreparado ao estagiar em uma escola com problemas agudos de violência. Era uma paisagem em quase tudo diferente daquela a que estava acostumado.

A preparação continuou a ser dirigida a uma escola ideal, no sentido de minimizar os problemas dos alunos e onde todos os recursos funcionam: "A gente é preparado para dar aula numa escola toda bonitinha... cheirosinha..." (licencianda de Pedagogia).

$\bigcirc$ estribilho repetido pelos participantes da pesquisa foi o de que não estavam preparados para agir, mas também que é muito difícil se preparar fora da ação. Na sua ansiedade, não conseguiram perceber que a preparação é continuada. Constataram o distanciamento entre as características da instituição formadora de educadores e as escolas onde o professor deve atuar. Embora numerosas pesquisas mostrem que a formação em nível superior do docente está relacionada positivamente ao rendimento dos alunos (Gomes, 2005), um dos licenciados afirmou: "É muito difícil que o ambiente acadêmico consiga... deixar o profissional pronto" (licenciando em Química).

Uma das descobertas dos estagiários, ainda pouco comprometidos com a escola, foi a perda do sentido da educação por professores, que, indiferentes, se atinham aos conteúdos e à preparação para o vestibular, o que foi um choque para o idealismo universitário. Estudantes insistiram na necessidade de novas metodologias que deixem claros os porquês e para quês de aprender Física, entre outros componentes curriculares, para que os alunos sejam bem sucedidos. É uma oposição ao "conteudismo" e o chamado para a mudança da escola em face do entrecruzamento de culturas na subjetivação do adolescente (Dubet, 2002, 2003). Mais adiante, o mesmo grupo focal, como outros de mais de uma licenciatura, com pequenas diferenças de matiz, revelou a mesma preocupação em face de si mesmos, jovens, enquanto estudam as disciplinas 
de formação pedagógica: não lhes dizem o para quê e não compreendem como se aplicam.

Para agravar o ordálio dos estagiários, várias escolas negavam-lhes informações, praticavam incivilidades e buscavam distorcer o estágio, tentando oferecer tarefas da menor relevância, em lugar do cumprimento das tarefas técnicas. Se os estabelecimentos se enquistam, cumprem os deveres ritual e burocraticamente, além de se afastarem das famílias e da comunidade, não surpreende que também ergam barreiras aos universitários, estrangeiros sociológicos (Simmel, 1926), com o seu perigoso olho crítico.

\section{A formação pedagógica pela voz dos formandos}

O leque de opiniões variou desde participantes que se disseram sem instrumental teórico e prático ao terminar o curso até os que se consideraram fundamentados para a atuação no magistério, sem receitas prontas, pois a realidade é imprevisível. Entre os primeiros concentraram-se os licenciandos de ciências matemáticas, enquanto os pedagogos predominaram na outra ponta. A maioria acusou falta de prática, visto que os estágios ficavam para o final, as atividades de campo ao longo do curso não eram suficientes e o preparo se tornava demasiadamente teórico - reações idênticas às dos educadores estudados por Lortie (2002) em outro tempo e contexto social.

A falta de relacionamento entre pesquisa e prática era um problema agudo na opinião da maioria. "As universidades formam um professor utópico", disse emblematicamente um deles. A mesma falta de prática foi responsabilizada pela desatenção às disciplinas de fundamentos da educação, para as quais muitos acordaram tarde para perceber sua utilidade. Por outro lado, ex-normalistas consideraram que suas experiências prévias facilitaram o seu desempenho nos cursos. Como autocrítica, alunos de ciências matemáticas frisaram a "exagerada preocupação com conteúdos, decoração de fórmulas etc.", quando, na realidade, a educação envolve a comunicação entre seres humanos.

Alguns afirmaram "não gostar muito" da formação pedagógica, o que remete à hierarquização dos saberes, segundo a velha sociologia do currículo (Young, 197I). O currículo é um âmbito de competição em que se hierarquizam os saberes conforme sua valorização, segundo os critérios de grupos que detêm o poder, especialmente dentro do sistema escolar. Desse modo, a 
A formação do professor..

formação pedagógica, voltada sobretudo para crianças e adolescentes - grupos vulneráveis da sociedade -, tende a ser menos valorizada que os conteúdos das chamadas ciências "duras". Essa prioridade depende do perfil desejado de docente, explícita ou implicitamente.

Um exemplo de como deveria ser o preparo docente partiu de um policial, cursando Física, que apresentou à sua turma suas experiências sobre o que fazer em diferentes casos, com base na lei. $\bigcirc$ trabalho foi vivamente recordado pela sua utilidade, inclusive porque as disciplinas não se referiam diretamente às violências nas escolas. $\bigcirc$ mesmo licenciando e policial declarou que é grande a falta de preparo na área de segurança, inclusive dos docentes em exercício: "Se houver um incêndio, o professor não sabe fazer a evacuação da sala de aula". Nesse sentido, destacou que as questões de segurança são mais bem tratadas na própria escola e não na universidade, porque levam em conta a realidade local.

Corroborando a literatura, é como se a educação superior formasse uma ilha precariamente ligada ao continente por uma ponte. Se já é difícil ultrapassar os limites da ilha, é mais árdua a missão de ingressar no continente, porque o licenciando pretende entrar num mundo que ainda não é dele. Como resultado, reclama que não tem prática, mas se cria um círculo vicioso, pois também não se abre facilmente o caminho para ela. Cabe considerar que a formação tem buscado a participação crescente do licenciando no estágio supervisionado, em vez de apor a formação pedagógica aos conteúdos. Assim, adota as diretrizes curriculares nacionais e, em coerência, os projetos pedagógicos dos cursos. Apesar disso, registraram-se afirmações de que o mergulho na realidade deveria ocorrer antes, com maior gradualismo e profundidade.

Segundo alguns sujeitos, a formação pedagógica desapontava por não corresponder às suas expectativas:

Eu tenho a impressão que a gente não tem o instrumental nem teórico, nem prático para encarar situações de violência. Eu fiz um curso agora há pouco na instituição [...] que eu participo, que era um curso de mediação de conflitos por uma cultura de paz. Lá tinha toda uma teoria e até vivência que a gente fazia para lidar até com situações extremas de violências, e a gente é totalmente despreparado, porque a tendência é entrar na onda, esquentar a cabeça e tudo "tá perdido, não adianta mais", né? (licencianda em Letras) 
Esta fala também se referiu à necessidade de oferecer formação continuada para "tapar buracos" da formação inicial ou para formar capacidades para os quais o licenciando não estava preparado ou sensibilizado. Por outro lado, refere-se a um fenômeno reiterado pelos sujeitos, isto é, reagir à violência dos alunos com maior violência ainda, em vez de preveni-la, como se isso fosse parte da autoridade e não uma desesperada tentativa de manter relações hierárquicas precárias. As teorias existem, mas não parecem se comunicar com a prática, ao passo que esta última aparentemente não volta para as teorias.

$\mathrm{Na}$ outra ponta do leque indicado encontraram-se falas entusiasmadas de licenciandos de Pedagogia. Algumas intervenções deixam transparecer discentes femininas, com outra caminhada intelectual, inspiradas, até certo ponto, por um idealismo missionário (Pereira, 1967), que, com a socialização profissional, talvez se encaixe em maior ou menor grau nos moldes da burocracia. Uma aluna deixou clara a relação entre pensamento e sentimento por meio da inspiração: "A gente estudou um livro [...] que foi um marco pra mim, porque ele me ajudou a compreender o significado de ser professor, o porquê de ser professor. Isso é uma coisa que mexe comigo até hoje" (licencianda de Pedagogia).

O efeito da prática também foi ressaltado como incentivador e, portanto, elemento expressivo de identificação com o magistério. Ademais, frisou-se o valor dos cursos para a vida, sob a forma de amadurecimento intelectual e emocional, por desenvolver a capacidade de lidar com situações complexas de relacionamento.

Luzes se acendem quanto a alternativas e novas percepções. Assim, apesar da crítica ao hiato entre teorias e práticas, participantes notaram que as licenciaturas hoje estão mais preocupadas com o complexo diálogo professoraluno. Por isso, ressaltaram não haver receitas para todas as situações. Ou seja, há necessidade de maior prática, mas, ao mesmo tempo, existe o reconhecimento de que a preparação das licenciaturas não pode ser fixa, em face de uma realidade cambiante. Em outras palavras, a prática, para responder à complexidade do real, precisa de flexibilidade e debate.

Daí emergiram sugestões, como a oferta e a obrigatoriedade de uma disciplina sobre as violências escolares (o que ocorre na universidade), o tratamento do tema notadamente pela Psicologia da Educação e a criação de um laboratório para simulação de situações de sala de aula. Com efeito, a 
A formação do professor..

licenciatura em Química criou o Programa de Iniciação Profissional Curricular quando estava em curso a coleta de dados desta pesquisa. Trata-se de uma série de atividades diversificadas para introduzir o futuro professor na sua prática, dependendo predominantemente da capacidade dos alunos de ser propositivos.

Outra proposta dos pesquisados foi igualmente significativa: superar a visão pessimista da educação brasileira, a convicção de que nada dá certo. Se o professor exerce um papel ativo, é responsabilidade de cada um e de cada licenciando contribuir para a reversão deste estado de coisas. É o caso de se indagar se pelo menos uma parte do corpo docente universitário derrapou do realismo para o pessimismo e utilizou versões discutíveis de algumas teorias.

Ao tratar da "licenciatura ideal", enfatizaram pontos para refletir: integrar mais os currículos; aprofundar o intercâmbio entre os professores; construir uma rampa suave das teorias às práticas, em vez de uma escadaria íngreme; começar mais cedo o trabalho de conclusão de curso; oferecer mais opções culturais para os alunos do período noturno; proporcionar maior incentivo à produção e disseminação de pesquisas. Como formar docentes para trabalhar com currículos integrados ou baseados em problemas e temas transversais, se as licenciaturas têm disciplinas compartimentadas, embora compatíveis entre si? Lembrando Beeby (1967), um dos maiores fatores de conservantismo do magistério está nos exemplos dos professores dos professores. É preciso inovar? Cabe aos docentes da educação superior dar a partida pelo próprio exemplo.

\section{O que dá certo e o que não dá?}

As críticas e propostas dos sujeitos da pesquisa são carapuças que se ajustam à universidade pesquisada, mas, pelo que apresentam em comum com tantas outras, cabem em inúmeras outras cabeças. Como a instituição não tem medo de espelhos, sua autoavaliação revela percepções e propostas valiosas.

Sumarizando opiniões, o que os estudantes definiram como mais negativo em tese na formação docente foi: professores passarem receitas fixas para problemas diversificados e complexos; ênfase às "teorias", dissociadas da prática, isto é, estudo generalista, sem destacar o que se extrai da pesquisa para a prática. Inversamente, quanto ao que dá certo dois pontos foram mais realçados: enlace constante entre teorias e práticas; vivências para compreender as teorias à luz da prática (Royer, 2002, 2003). 
São ilustrativos os resultados da avaliação feita por um grupo focal sobre a disciplina optativa a respeito das violências nas escolas, oferecida com a orientação do Observatório de Violências nas Escolas - Brasil. O que mais se destacou foi: relacionou teorias e práticas; não deu receitas, ensinou a buscar soluções; preparou para antecipar e resolver problemas, em vez de reagir a eles, evitando partir para o confronto com os discentes; incentivou os licenciandos a visitar escolas, aplicar técnicas de pesquisa e retornar à sala de aula para apresentar e discutir os resultados; contribuiu para evitar a banalização das violências, pela inação e omissão dos professores; revelou que os preconceitos sociais e étnicos também são violências, inclusive praticadas pela escola; mostrou que, para ser professor, é preciso uma formação mais humanística.

Duas alunas declararam: "Hoje eu me considero muito mais preparada", "A gente vê outro mundo ali".

Aparentemente, apesar das boas intenções, pratica-se em muitos casos o avesso do que recomendou Royer (2002, 2003, 2003a). Parece que em numerosos casos as teorias e as pesquisas vivem em compartimentos distintos, só têm valor em si e não se puxa o fio à meada para ligá-las às vivências. Um recurso subutilizado é fazer dramatizações e outras atividades, além de se preocupar constantemente em enlaçar o que fazer, por que fazer e como fazer. Os valores são um referencial básico da educação para superar as violências e construir a cultura de paz. Os currículos e programas seriam definidos mais em termos dos conteúdos relevantes para a academia ou dos problemas a enfrentar?

\section{CONCLUSÕES}

Ao entrelaçar a literatura e os resultados desta pesquisa, divididos entre as percepções e propostas dos licenciandos, pode-se observar diversas convergências, lacunas e interrogações.

Os participantes deixaram claras suas preocupações com a descontinuidade entre o mundo da instituição formadora e o da escola, o que leva ao choque de realidade, amplamente evidenciado pela literatura. Aparentemente, falta a percepção de que as licenciaturas oferecem fundamentos científicos para o papel de professor. Uma lacuna foi a falta de compreensão maior da adolescência e da juventude, do seu protagonismo e das suas culturas. Uma tendência preocupante é o risco de fatalismo em face das relações estabelecidas entre 
A formação do professor..

exclusão social e fracasso e violências escolares. Com isso, além da tentativa de amortecer as sensações de impotência e incompetência profissional, tende-se a culpar o aluno, a família e a vizinhança.

Ou a contribuição das teorias e das pesquisas não é percebida ou não é oferecida em bases sólidas, relacionando teorias e práticas. Nessa relação entre a ilha e o continente, dez anos após a sanção da Lei de Diretrizes e Bases, a formação em nível médio para o magistério vai ficando para trás, embora valorizada pelos fundamentos que proporcionou a diversos licenciandos.

A sociedade insere-se hoje de modo mais ou menos perverso e oneroso na mundialização, o que requer a elevação do nível de escolaridade dos docentes e o desenvolvimento da educação superior de massa, como já existe a escola básica de massa. Novos problemas emergem, com o desvelar de certas formas de violência e o aparecimento e a multiplicação de outras. Entretanto, continua a busca de construir pontes entre a ilha e o continente, entre as instituições formadoras, de um lado, e as escolas e a sociedade, de outro.

Os licenciandos pesquisados pediram mais: um contato ainda mais íntimo com a prática, além dos trabalhos de campo existentes, mais cedo e não só na etapa final do estágio supervisionado. Em outras palavras, há necessidade de um gradiente mais bem construído entre a formação e a prática de sala de aula, com a certeza, porém, de que não existem fórmulas nem receitas. Eles manifestaram mais interesse em aprender a pescar do que em receber peixes padronizados.

As diferentes alternativas para a formação de professores antes apresentadas merecem séria reflexão pelos resultados concretos que trazem. A realidade não é, está. Por isso, o dever dos educadores é contribuir para alterar o status quo, ou seja, elevar o nível qualitativo e não só a titulação dos docentes. Não adianta bater o pé nas condições de estudo e trabalho de alunos e professores.

Se as licenciaturas são consideradas cursos menores, que qualquer um pode fazer; se esses chegam à banalização, se para o Estado e a sociedade vale simplesmente ter professores, tenham eles a capacidade e a ética que tiverem, então é contraditório denunciar a educação a partir dos resultados das avaliações nacionais e internacionais.

Tal denúncia se afigura uma farsa eficaz, é deixar como está para ver como fica e, assim, manter a estratificação social e os privilégios. A educação básica, ou a vaga na escola, é para todos, mas não é a mesma para todos em 
qualidade. A educação incompetente é um lobo em pele de ovelha: finge que é redentora, que todos têm oportunidades, mas por baixo da pele mantém as disparidades e confirma a exclusão social. Como se percebe, o Brasil precisa de modificações urgentes nas licenciaturas.

O mais importante é que, perante as novas circunstâncias, os sujeitos da pesquisa se mostraram, ao mesmo tempo, inquietos, críticos e propositivos. Deixaram claro que não se acomodem na socialização profissional. É um bom sinal para o futuro, a ser encarado com a virtude da esperança.

\section{REFERÊNCIAS BIBLIOGRÁFICAS}

ABRAMOVAY, M.; RUA, M. G. Violências nas escolas. Brasília: Unesco, 2002.

ABRAMOVAY, M. et al. Cotidiano das escolas: entre violências. Brasília: Unesco, 2006.

ARTINOPOLOU, V. A Violência escolar na Grécia: panorama das pesquisas e estratégias de ação. In: DEBARBIEUX, E; BLAYA, C. (orgs.) Violência nas escolas: dez abordagens europeias. Brasília: Unesco, 2002. p. $153-174$.

BARRÈRE, A.; SEMBEL, N. Sociologie de l'éducation. Paris: Nathan, 2002.

BARROSO, J. Ordem disciplinar e organização pedagógica. In: CORREIA, J. A.; MATOS, M. (orgs.) Violência e violências da e na escola. Porto: Afrontamento; Centro de Investigação e Intervenção Educativas, 2003. p.63-72.

BEEBY, C. E. Educação e desenvolvimento econômico. Rio de Janeiro: Zahar, 1967.

BLAYA, C. School violence and the professional socialization of teachers: the lessons of comparatism. Journal of Educational Administration, Bradford, v.4I, n.6, p.650-668, 2003.

Violences et maltraitances en milieu scolaire. Paris: Armand Colin, 2006.

BLOMART, J. Evitando a violência no ambiente das escolas primárias. In: DEBARBIEUX, E; BLAYA, C. (orgs.) Violência nas escolas: dez abordagens europeias. Brasília: Unesco, 2002. p.35-62.

BROUWER, N.; KORTHAGEN, F. Can teacher education make a difference? American Educational Research Journal, Washington, v.42, n. I , p. I53-224, 2005.

CASTRO SANTANDER, A. Prevenir las violencias: la deuda de enseñar a vivir con los demás. Revista Iberoamericana de Educación, Madrid, v.4, n.38, p. I-6, 2005.

CHRISPINO, A.; CHRISPINO, R. S. P. Políticas educacionais de redução da violência: mediação do conflito escolar. São Paulo: Biruta, 2002. 
A formação do professor..

CHUPIN, J. Afrique: la chicotte ou l'école à bâtons rompus. Le Monde de l'Éducation, Paris, n.343, p.44-45, jan. 2006.

DEBARBIEUX, E. Violência na escola: um desafio mundial? Lisboa: Instituto Piaget, 2007.

DEBARBIEUX, E.; BLAYA, C. (orgs.) Violência nas escolas e políticas públicas. Brasília: Unesco, 2002.

DELORS, J. et al. Educação: um tesouro a descobrir. 4.ed. São Paulo: Cortez; Brasília: MEC, Unesco, 2000. (Relatório para a Unesco da Comissão Internacional sobre Educação para o Século XXI)

DUBET, F. Le Déclin de l'institution. Paris: Seuil, 2002.

A Escola e a exclusão. Cadernos de Pesquisa, São Paulo, n. 11 9, p.29-45, jul. 2003.

DUBET, F; MARTUCCELLI, D. À l'école: sociologie de l'experience scolaire. Paris: Seuil, 1996.

DURU-BELLAT, M.; VAN ZANTEN, A. Sociologie de l'école. 3. ed. Paris: Armand Collin, 2006.

FELOUZIS, G. A Eficácia dos professores. Porto: Rés, 2000.

FILMUS, D. et al. Violência na escola: América Latina e Caribe. Brasília: Unesco, 2003.

FORACCHI, M. M. O Professor e a situação de ensino: uma análise de sociologia da educação. Sociologia, São Paulo, v.22, n. I, p.29-4I, 1960.

FREITAS, M. N. C. Organização escolar e socialização profissional de professores iniciantes. Cadernos de Pesquisa, São Paulo, n. I I 5, p. I2-24, mar. 2002.

GOMES, C. A. A Educação em novas perspectivas sociológicas. 4. ed. São Paulo: Pedagógica e Universitária, 2005.

LORTIE, D. C. Schoolteacher: a sociological study. 2. ed. Chicago: University of Chicago Press, 2002.

MELLO, G. N. de. Magistério de $1^{\circ}$ grau: da competência técnica ao compromisso político. São Paulo: Cortez, 1982.

OLIVEIRA, M. G. P.; GOMES, C. A. Como docentes veem valores e violências escolares no ensino médio. Revista Brasileira de Política e Administração da Educação, Rio de Janeiro, v.20, n. I, p.45-70, jan./jun. 2004.

ORTEGA, R. O Projeto de Sevilha contra a violência nas escolas: um modelo de intervenção educacional de natureza ecológica. In: DEBARBIEUX, E.; BLAYA, C. (orgs.) Violência nas escolas: dez abordagens europeias. Brasília: Unesco, 2002. p. 197-222. 
ORTEGA, R.; REY, R. del. Estratégias educativas para a prevenção da violência. Brasília: Unesco, 2002.

PEREIRA, L. A Escola numa área metropolitana: crise e racionalização de uma empresa pública de serviços. São Paulo: Pioneira; Edusp, 1967.

O Professor primário metropolitano. Rio de Janeiro: Centro Brasileiro de Pesquisas Educacionais, 1963.

ROYER, E. A. Condutas agressivas na escola: pesquisas, práticas exemplares e formação de professores. In: SEMINÁRIO DE VIOLÊNCIAS NAS ESCOLAS: DESAFIOS E ALTERNATIVAS: VIOLÊNCIAS NAS ESCOLAS. Anais... Brasília: Unesco, UNDP, 2003. p.57-78.

Violência escolar e as políticas de formação de professores. In: DEBARBIEUX, E.; BLAYA, C. (orgs.) Violências nas escolas e políticas públicas. Brasília: Unesco, 2002. p. $25 \mathrm{I}-265$.

What Galileo knew: school violence, research, effective practices and teacher tranining. Journal of Educational Administration, Bradford (United Kingdom), v.4I, n.6, p.640-647, 2003a.

SIMMEL, G. Sociologia. Madrid: Revista de Occidente, 1926.

SOEIRO, J. Violências e desencontros. CORREIA, J. A.; MATOS, M. (orgs.) Violência e violências da e na escola. Porto: Afrontamento, Centro de Investigação e Intervenção Educativas, 2003. p.3|-34.

TESTANIÈRE, J. Chahut traditionnel et chahut anomique dans l'enseignement du second degrée. Revue Française de Sociologie, Paris, v.8, n.esp., p. 17-32, 1967.

YOUNG, M. An approach to the study of curriculum as socially organized knowledge. In: YOUNG, M. (org.) Knowledge and control : new directions for the sociology of education. London: Collien MacMilan, 197I. p. 19-46.

Repensando la formación de profesores para un futuro globalizado: lecciones derivadas de la experiencia inglesa. In: ÁVALOS, B.; NORDENFLYCHT, M. E. (orgs.) La formación de profesores: perspectiva y experiencias. Santiago de Chile: Aula XXI, Santillana, 1999. p.|68-187.

YOUNG, M. (org.) Knowledge and control: new directions for the sociology of education. Londres: Collier MacMillan, 197I. p. 19-46.

Recebido em: junho 2007

Aprovado para publicação em: agosto 2007 